\title{
The cytotoxic and immunogenic hurdles associated with non-viral mRNA-mediated reprogramming of human fibroblasts
}

\author{
Katharina Drews $^{\text {a,b, }}{ }^{\text {, Geertrui Tavernier }}{ }^{\mathrm{c}, 1}$, Joseph Demeester ${ }^{\mathrm{c}}$, Hans Lehrach $^{\mathrm{a}}$, \\ Stefaan C. De Smedt ${ }^{\mathrm{c}}$, Joanna Rejman ${ }^{\mathrm{c}}$, James Adjaye ${ }^{\mathrm{a}, \mathrm{d}, *}$ \\ ${ }^{a}$ Molecular Embryology and Aging Group, Department of Vertebrate Genomics, Max Planck Institute for Molecular Genetics, Ihnestr. 63-73, 14195 Berlin, Germany \\ ${ }^{\mathrm{b}}$ Department of Biology, Chemistry and Pharmacy, Institute of Chemistry and Biochemistry, Freie Universität Berlin, Takustr. 3, 14195 Berlin, Germany \\ ${ }^{\mathrm{c}}$ Research Group on Nanomedicines, Ghent University, Harelbekestraat 72, 9000 Ghent, Belgium \\ ${ }^{\mathrm{d}}$ Institute for Stem Cell Research and Regenerative Medicine, Heinrich Heine University Duesseldorf, Moorenstr. 5, 40225 Duesseldorf, Germany
}

\section{A R T I C L E I N F O}

\section{Article history:}

Received 19 January 2012

Accepted 9 February 2012

Available online 28 February 2012

\section{Keywords:}

mRNA

Reprogramming

Lipofection

Transfection

Immune response

\begin{abstract}
A B S T R A C T
Delivery of reprogramming factor-encoding mRNAs by means of lipofection in somatic cells is a desirable method for deriving integration-free iPSCs. However, the lack of reproducibility implies there are major hurdles to overcome before this protocol becomes universally accepted. This study demonstrates the functionality of our in-house synthesized mRNAs expressing the reprogramming factors (OCT4, SOX2, KLF4, c-MYC) within the nucleus of human fibroblasts. However, upon repeated transfections, the mRNAs induced severe loss of cell viability as demonstrated by MTT cytotoxicity assays. Microarray-derived transcriptome data revealed that the poor cell survival was mainly due to the innate immune response triggered by the exogenous mRNAs. We validated the influence of mRNA transfection on key immune response-associated transcript levels, including IFNB1, RIG-I, PKR, IL12A, IRF7 and CCL5, by quantitative real-time PCR and directly compared these with the levels induced by other methods previously published to mediate reprogramming in somatic cells. Finally, we evaluated chemical compounds (B18R, chloroquine, TSA, Pepinh-TRIF, Pepinh-MYD), known for their ability to suppress cellular innate immune responses. However, none of these had the desired effect. The data presented here should provide the basis for further investigations into other immunosuppressing strategies that might facilitate efficient mRNA-mediated cellular reprogramming in human cells.
\end{abstract}

(c) 2012 Elsevier Ltd. All rights reserved.

\section{Introduction}

Reprogramming of somatic cells toward pluripotency brought a promise in the field of regenerative medicine. The first induced pluripotent stem cells (iPSCs) were generated by introduction of transcription factors into human fibroblasts by means of retroviruses. It was achieved by the group of Yamanaka, who transduced fibroblasts with four transcription factors, namely OCT4, SOX2, KLF4 and c-MYC [1,2]. Other research groups refined the protocol by using less or other factors [3-5] or by implementing small molecules to increase the efficiency [4,6-8]. iPSCs produced this way, successfully serve as a tool in disease modeling or drug screening. Nonetheless, they are not suitable to generate patient-specific transplantable cells in a clinical setting because of the abundant

\footnotetext{
* Corresponding author. Molecular Embryology and Aging Group, Department of Vertebrate Genomics, Max Planck Institute for Molecular Genetics, Ihnestr. 63-73, 14195 Berlin, Germany. Tel.: +49 308413 1203; fax: +49 3084131128 .

E-mail address: adjaye@molgen.mpg.de (J. Adjaye).

1 These authors contributed equally to this work.
}

insertional mutagenesis. Therefore, one of the main focuses in the field has been to develop methods, which avoid genome insertions when delivering the transcription factors to somatic cells. Accordingly, the plasmids encoding the reprogramming factors have been delivered to mouse and/or human cells by means of repeated nonviral transfections [9], non-integrating, episomal viral vectors $[7,10]$, or using excisable vectors [11,12]. Even though they succeeded in reducing genomic insertions markedly, the risk of modifying the host genome has never been eliminated completely. Zhou et al. generated iPSCs completely devoid of genomic insertions by introducing recombinant transcription factor proteins [13]. This method, however, was very inefficient. Recently, two alternative methods have been described to generate iPSCs, both inherently incapable of causing insertional mutagenesis. To induce pluripotency Warren et al. delivered the transcription factors as mRNAs complexed with commercially available cationic lipids and claimed high reprogramming efficiency [14]. This, however, required 17 daily mRNA transfections, which has been shown to severely compromise cell viability [15]. Miyoshi et al. produced 
iPSCs by transfection of mature human embryonic stem cellassociated miRNAs [16]. Despite these achievements, the lack of follow-up publications implies there are major hurdles to overcome before these approaches become reproducible and routinely applicable for successful cellular reprogramming [17].

We are experienced in both non-viral mRNA delivery into cells $[18,19]$ and the derivation of human iPSCs $[6,20-22]$. We have previously applied a slightly adjusted mRNA reprogramming protocol, which enabled us to reduce the number of transfections, to successfully induce the onset of reprogramming in mouse embryonic fibroblasts [23]. In this study we assessed the early response in terms of expression of pluripotency-associated genes upon transfecting human neonatal fibroblasts with mRNAs encoding the Yamanka factors and studied in detail the impact of repeated mRNA transfections on the viability and transcriptome of human neonatal fibroblasts.

\section{Materials and methods}

\subsection{Cell culture}

Human foreskin fibroblasts (HFF1 and BJ, SCRC-1041 and SCRC-2522 from ATCC, respectively) were cultured in DMEM (Life Technologies, Darmstadt, Germany) supplemented with $10 \%$ fetal bovine serum (FBS, Biochrom, Berlin, Germany) at $37^{\circ} \mathrm{C}, 5 \% \mathrm{CO}_{2}$

\subsection{In vitro mRNA synthesis}

Previously described plasmids (containing a T7 RNA polymerase promoter) encoding a single reprogramming factor (OCT4, SOX2, KLF4 or c-MYC) were purchased from Addgene (Cambridge, USA) [14]. The plasmid encoding green fluorescent protein (GFP) (pGEM4Z-EGFP-A64, kindly provided by Prof. Dr. E. Gilboa, Duke University Medical Center, Durham, NC, USA) was previously described by Nair et al. [24]. To produce mRNAs, plasmids were first purified using a QIAquick PCR purification kit (Qiagen, Venlo, Netherlands) and linearized using restriction enzymes (XbaI for plasmids encoding reprogramming factors and SpeI for the GFPcoding plasmid). Linearized plasmids were used as templates for the in vitro transcription reaction using the T7 mMessage mMachine kit according to the manufacturer's instructions (Ambion, Lennik, Belgium). This resulted in the production of $\mathrm{m}$ (GFP) that was both capped and polyadenylated. All the other mRNAs (m(OCT4), $\mathrm{m}(\mathrm{SOX} 2), \mathrm{m}(\mathrm{KLF} 4)$ and $\mathrm{m}(\mathrm{c}-\mathrm{MYC})$ ) were capped and subsequently polyadenylated with a poly(A) tailing kit supplied by Ambion. mRNAs were purified by DNase I digestion followed by $\mathrm{LiCl}$ precipitation and a 70\% ethanol wash. The mRNA concentration was determined by measuring the absorbance at $260 \mathrm{~nm}$ using a NanoDrop spectrophotometer (NanoDrop Technologies, Wilmington, DE, USA) and then mRNA was stored in small aliquots at $-80{ }^{\circ} \mathrm{C}$ at a concentration of $1 \mu \mathrm{g} / \mu \mathrm{l}$.

mRNAs encoding the four Yamanaka factors including both pseudouridine and 5-methylcytidine-modified nucleotides were purchased from Stemgent (Miltenyi, Bergisch Gladbach, Germany).

\section{3. mRNA transfection}

HFF1 cells were seeded one day prior to the experiment (200,000 cells/well in 6well-plates for qRT-PCR experiments, 100,000 cells/well in 12-well-plates for cytotoxicity and immunostaining experiments). Either $4 \mu \mathrm{g}$ of m(GFP) or a $4 \mu \mathrm{g}$ mixture of the four separate mRNAs (equal amounts of m(OCT4), m(SOX2), m(KLF4), m(cMYC)), either produced as described earlier or commercially bought, were prediluted in $46 \mu \mathrm{l}$ Opti-MEM (Invitrogen, Merelbeke, Belgium). These mRNA dilutions were complexed with $4 \mu \mathrm{l}$ of Lipofectamine RNAiMAX (LF) $(1 \mathrm{mg} / \mathrm{ml}$, Invitrogen, Merelbeke Belgium), also pre-diluted in $46 \mu$ l Opti-MEM. After $10 \mathrm{~min}$ of incubation at RT, $900 \mu \mathrm{l}$ of Opti-MEM were added and the complete solution was added to one well (6-well-plate) or divided over two wells (12-well-plate) (after removal of growth medium). After $2 \mathrm{~h}$ of incubation with the cells, the complexes were removed and regular growth medium was added.

\subsection{Analysis of GFP expression}

To assess the number of GFP-positive cells, culture medium was removed from the wells and the cells were washed with PBS. After detaching the cells with trypsin $(0.05 \%$, Life Technologies) and centrifugation, the cells were re-suspended in flow buffer (PBS containing $1 \%$ BSA and $0.1 \%$ azide). The samples were kept on ice until GFP expression was evaluated by a Beckman Coulter Flowcytomer FC500, equipped with a $488 \mathrm{~nm}$ laser. Images showing GFP expression in cells transfected with Lipofectamine/m(GFP) complexes were taken with a confocal microscope LSM 510 (Zeiss, Oberkochen, Germany).

\subsection{Immunostaining and microscopy analysis}

To visualize the nuclear expression of the reprogramming factors, cells were fixed with 4\% paraformaldehyde (Electron Microscopy Sciences, Hatfield, PA, USA) for 12 min at RT, washed two times with $0.05 \%$ Tween 20 (Sigma, Munich, Germany) in PBS (PBST) and permeabilized with 1\% Triton X-100 (Sigma) in PBS. After two more washes with PBST, cells were blocked with $5 \%$ FBS and $1 \%$ Bovine Serum Albumin (BSA, Sigma) in PBST for $1 \mathrm{~h}$ at RT. Primary antibodies to detect the reprogramming factor proteins were purchased from Santa Cruz Biotechnologies (Heidelberg, Germany): OCT4 (Cat. No. sc-5279), SOX2 (Cat. No. sc-17320), KLF4 (Cat. No. sc-20691) and c-MYC (Cat. No. sc-764). Secondary antibodies were bought from Life Technologies: Alexa Fluor 594 chicken anti-goat IgG (Cat. No. A21468), Alexa Fluor 488 goat anti-mouse IgG (Cat. No. A11001) and Alexa Fluor 488 donkey antirabbit IgG (Cat. No. A21206). Nuclei were counterstained with DAPI (100 ng/ml Vector Laboratories, Burlingame, CA, USA) diluted with PBST (12 min, RT). Cells were visualized using a confocal microscope LSM 510.

\subsection{Toxicity assays}

HFF1 cells were plated in 12-well-plates $(90,000$ cells/well) and incubated with mRNA complexes prepared as described above for $2 \mathrm{~h}$. Transfections were performed every day. Cell viability was evaluated $24 \mathrm{~h}$ post-transfection by an MTT assay (Roche, Vilvoorde, Belgium) performed according to the manufacturer's instructions.

\subsection{RNA isolation}

Total RNA was isolated from cell lysates using the RNeasy Mini Kit (Qiagen, Germantown, MD, USA) according to the manufacturer's instructions. The concentrations of the isolated RNAs were determined by measuring the absorbance at $260 \mathrm{~nm}$ using a NanoDrop spectrophotometer and purity was assessed by agarose gel electrophoresis.

\subsection{Illumina bead chip hybridization and data analysis}

The hybridization protocol has been described earlier by Mah et al. [25]. Briefly, $500 \mathrm{ng}$ total RNA were used as input for amplification and labeling reactions (Illumina TotalPrep RNA Amplification Kit, Ambion) prior to hybridization onto Illumina HumanRef-8 v3.0 Expression BeadChips on the Illumina BeadStation 500 platform (Illumina, San Diego, CA, USA, www.illumina.com). Raw data were converted to background-subtracted, normalized ("rank invariant" algorithm) data with the help of the Gene Expression Module version 1.8.0 provided with the GenomeStudio software (Illumina). Genes were considered "present" if the "Detection P-Value" $p_{\text {det }}<0.01$. Significant differential gene expression with respect to Lipofectaminetreated control cells ("mock") required $p_{\text {det }}<0.01$ in at least one of the samples under investigation and was defined by 1.5 fold up- or down-regulation in combination with an FDR-adjusted (Benjamini and Hochberg algorithm) "Diff $P$-Value" $p_{\text {adj }}<0.05$ as output by GenomeStudio. The heatmap was created using the gplots package in $\mathrm{R}[26,27]$. Functional annotation and analyses for KEGG pathway enrichment were conducted using official gene symbols and default settings of the DAVID platform version 6.7 (http://david.abcc.ncifcrf.gov/home.jsp) $[28,29]$. Identification of interferon-regulated genes was achieved with the help of the Interferome database [30]. The data discussed in this publication have been deposited in NCBI's Gene Expression Omnibus [31] and are accessible through GEO Series accession number GSE34943 (http://www.ncbi.nlm.nih.gov/geo/query/acc cgi?acc $=$ GSE34943).

\section{9. $q R T-P C R$}

For M-MLV-driven reverse transcription (Affymetrix/USB Corporation, Cleveland, OH, USA), $1 \mu \mathrm{g}$ total RNA was diluted to $9.5 \mu \mathrm{l}$ with RNase/DNase-free distilled water $\left(\mathrm{dH}_{2} \mathrm{O}\right.$, Life Technologies $)$ and $0.5 \mu$ ligo-dT $(1 \mu \mathrm{g} / \mu \mathrm{l}, 15 \mathrm{mer})$ were added. The mixture was incubated at $72{ }^{\circ} \mathrm{C}$ for $5 \mathrm{~min}$ and cooled down on ice. $15 \mu \mathrm{l}$ of a master mix were added, containing the following components (per reaction): $9.4 \mu$ RNase/ DNase-free $\mathrm{dH}_{2} \mathrm{O}, 5.0 \mu \mathrm{l} 5 \mathrm{X}$ M-MLV reaction buffer (USB), $0.5 \mu \mathrm{l}$ dATP, dCTP, dGTP, dTTP mix (25 mM each, USB), $0.1 \mu \mathrm{l}$ M-MLV (USB) and the mixture was incubated at $42{ }^{\circ} \mathrm{C}$ for $1 \mathrm{~h}$. The enzyme was inactivated at $65^{\circ} \mathrm{C}$ for $10 \mathrm{~min}$. The resulting cDNA was kept at $4{ }^{\circ} \mathrm{C}$ for direct use or stored at $-20^{\circ} \mathrm{C}$. Quantitative real-time polymerase chain reaction (qRT-PCR) was performed in 384-well-plates (Applied BioSystems, Foster City, CA) using the SYBRGreen PCR Master Mix (Applied Biosystems). Reactions were carried out on the ABI PRISM 7900HT Sequence Detection System (Applied Biosystems) as previously described [32]. Triplicate amplifications were carried out per gene with three wells without template serving as negative controls. АСTB was amplified along with the target genes as endogenous control for normalization. All primer sequences are provided in Supplementary Table S1.

Data analysis was carried out using the ABI PRISM SDS 2.2.1 software (Applied Biosystems) and Microsoft Excel (Microsoft Corporation, Redmond, WA, USA) Housekeeping gene-normalized, relative mRNA levels of each gene (biological sample versus reference) were calculated based on the $2^{-\Delta \Delta \mathrm{CT}}$ method [33]. Data are 
presented as mean LOG2 ratios with respect to biological controls and standard deviation.

\subsection{Analysis of the immune response to different nuclear reprogramming approaches}

HFF1 cells were plated in 6-well-plates (200,000 cells/well) one day prior to the experiments. Per well the cells were transduced or transfected with (1) a 1:1:1:1 cocktail of retroviruses encoding four reprogramming factors (OSKM) or a GFPencoding retrovirus equivalent to the amount of a single reprogramming factor (production of retroviruses and transduction procedure were described earlier $[6,20,22])$ or (2) 100 pmol of a 1:1:1:1:1 mix composed of the miRNAs miR302a miR302b, miR302c, miR302d and miR367 or a non-target (scrambled) miRNA (Ambion) or (3) $4 \mu \mathrm{g}$ of in-house synthesized unmodified or purchased modified mRNAs encoding the four reprogramming factors or mRNA encoding GFP. The cells were harvested $24 \mathrm{~h}$ after transfection and RNA was isolated for microarray-based global gene expression analysis and the analysis of immune response-associated gene regulation by qRT-PCR (as described above). To determine the immunomodulatory effect of different substances upon mRNA transfection, cells were preincubated with these substances $1 \mathrm{~h}$ prior to transfection, during the incubation of the complexed RNA with the cells and $24 \mathrm{~h}$ post-transfection at the following concentrations: $200 \mathrm{ng} / \mathrm{ml}$ Vaccinia B18R (eBioscience/biocompare), 5, 50, $100 \mu \mathrm{M}$ Chloroquine (Sigma), 50, 100, $500 \mathrm{nM}$ Trichostatin A (Sigma), $20 \mu \mathrm{M}$ Pepinh-TRIF (InvivoGen, San Diego, CA, USA), $20 \mu \mathrm{M}$ Pepinh-MYD (InvivoGen).

\section{Results}

\subsection{Transfection of HFF1 cells with mRNA encoding green fluorescent protein or reprogramming factors}

Human foreskin fibroblasts (HFF1) were transfected with $4 \mu \mathrm{g}$ of mRNAs encoding green fluorescent protein (m(GFP)) complexed with $4 \mu \mathrm{l}$ Lipofectamine RNAiMAX (LF) as described in Materials and methods. The flow cytometry and microscopic analysis presented in Fig. 1 shows that approximately 85\% of cells expressed GFP with a very high intensity per cell. Next, we transfected HFF1 cells with a mixture of equal amounts of mRNAs encoding the Yamanaka factors (m(OCT4), m(SOX2), m(KLF4), m(c-MYC)). After $24 \mathrm{~h}$, the cells were fixed, stained and analyzed by microscopy. Protein expression was clearly detectable (OCT4, SOX2) or increased above endogenous background levels (KLF4, c-MYC) when compared to mock-transfected control cells (Fig. 2). Importantly, the images confirmed the nuclear localization of the expressed factors.

\subsection{Viability of HFF1 cells transfected daily with mRNA lipoplexes}

Transfection data can be properly valued only if the potential toxic effects of the system are evaluated. To determine the effect of the transfection protocol on cell viability, HFF1 cells were transfected daily with Lipofectamine complexes carrying mRNAs encoding the Yamanaka factors. Cell viability was assessed $24 \mathrm{~h}$ after each transfection. The data presented in Fig. 3 demonstrate that there was no significant change in the viability of HFF1 cells $24 \mathrm{~h}$ after the first transfection. From day 2, however, the number of cells in culture diminished progressively. No cells survived seven consecutive transfections.

\subsection{Comparative global gene expression analysis of reprogramming factor mRNA-transfected and mock-transfected human fibroblasts}

Several attempts to induce pluripotency in HFF1 and BJ cells by repeated lipofection of the mRNAs encoding the reprogramming factors failed due to progressive loss of cell viability. We decided to investigate the reason for this massive cell death. It is known that transfection of poly(A)-tailed mRNA into human fibroblast cells induces interferon response [15,34]. To get a more detailed insight into which pathways are involved in the immediate response, we analyzed the transcriptomes of two human fibroblast cell lines (HFF1 and BJ) transfected with mRNAs encoding the reprogramming factors and mock-transfected, LF-treated controls. The analysis was performed $24 \mathrm{~h}$ post-transfection. The results were compared with the transcriptomes of untreated wild-type human neonatal fibroblasts (HFF1 and BJ cells), human embryonic stem cells (ESCs, lines $\mathrm{H} 1$ and H9) and human induced pluripotent stem cells derived from HFF1 and BJ cells (FiPSCs) generated and maintained in our laboratory $[20,21]$. Hierarchical clustering based on the global gene expression of all samples demonstrated a clear separation of fibroblasts transfected with mRNAs encoding the reprogramming factors from wild-type and mock-transfected fibroblasts as well as from human FiPSCs and ESCs (Fig. 4a). Accordingly, linear correlation coefficient analysis revealed that mRNA-transfected fibroblasts shared decreasing numbers of expressed genes with mock-transfected fibroblasts $\left(R^{2}=0.84\right)$, wild-type fibroblasts $\left(R^{2}=0.73\right)$, FiPSCs $\left(R^{2}=0.60\right)$ and ESCs $\left(R^{2}=0.56\right)$. Interestingly, mock-transfected and wild-type fibroblasts are closer to FiPSCs and ESCs $\left(R^{2} \approx 0.71\right)$ than are reprogramming factor-transfected fibroblasts from FiPSCs and ESCs $\left(R^{2} \approx 0.58\right)$ (Fig. $4 \mathrm{~b}$ ). This emphasizes that the active transcriptome of reprogramming factor mRNA-transfected fibroblasts is indeed different from both the original donor cells as well as the pluripotent cell lines and that an overall shift toward a pluripotent cell type has not yet occurred.

To investigate if, nevertheless, potential pluripotency-associated genes are up-regulated as early as $24 \mathrm{~h}$ after transfection of the reprogramming factors, we generated a Venn diagram based on "detected" genes in mock control cells, reprogramming factortransfected fibroblasts and the union of FiPSCs and ESCs (the
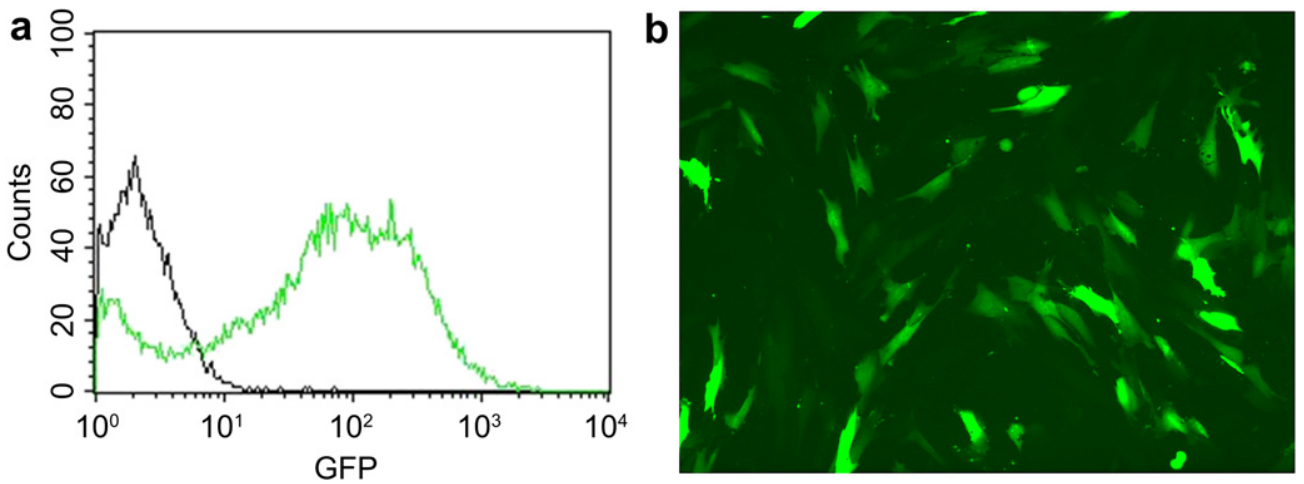

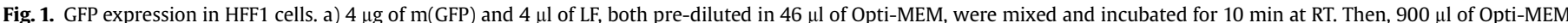

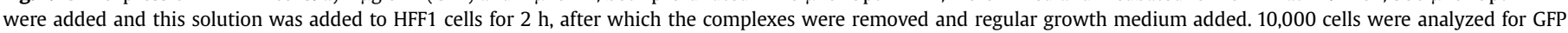

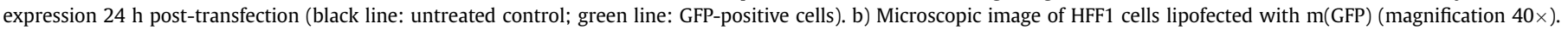



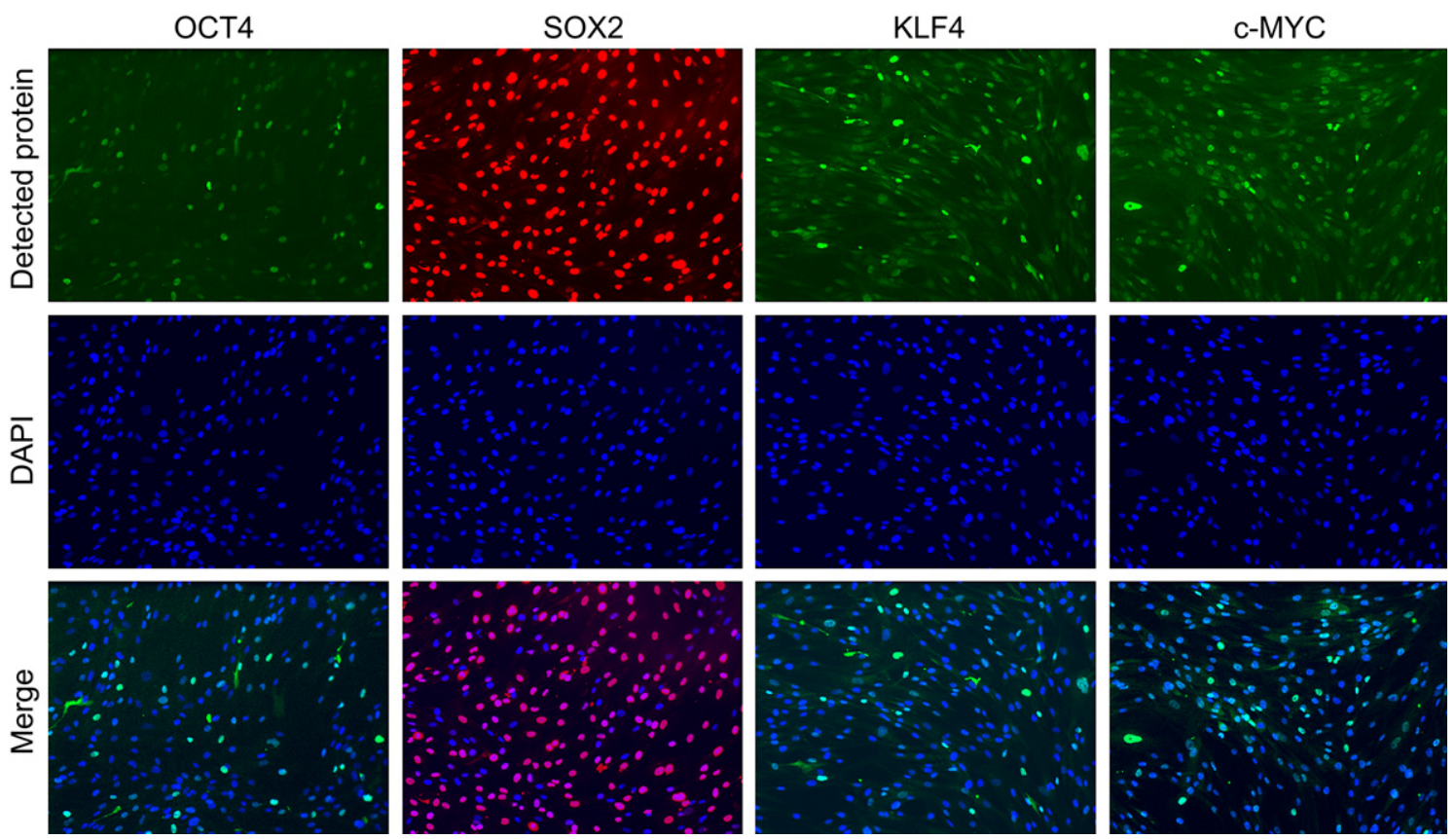

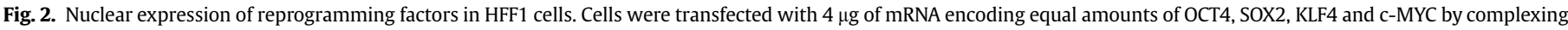
with $4 \mu \mathrm{l} \mathrm{LF}$ as described in Materials and methods. After $24 \mathrm{~h}$, cells were immunostained for the transfected factors. The nuclei were stained with DAPI (magnification $40 \times$ ).

overlapping genes in these two pluripotent cell types), which is presented in Fig. 4c. The list of 148 putative pluripotency-associated genes, which overlap in reprogramming factor-transfected fibroblasts and the union of FiPSCs and ESCs, is given in Supplementary Table S2. It is enriched for cellular membrane and transmembrane protein-encoding genes and genes associated with cell-cell signaling such as SYT1, CXCR7, CEACAM1, BST2 and CXCL6.

To analyze the changes induced by transfection with mRNAs encoding reprogramming factors we filtered the global gene expression data for genes, which were significantly up- or downregulated in reprogramming factor-transfected fibroblasts with respect to mock-transfected control fibroblasts. As shown in Fig. 4d, a total of 993 genes were significantly differentially regulated

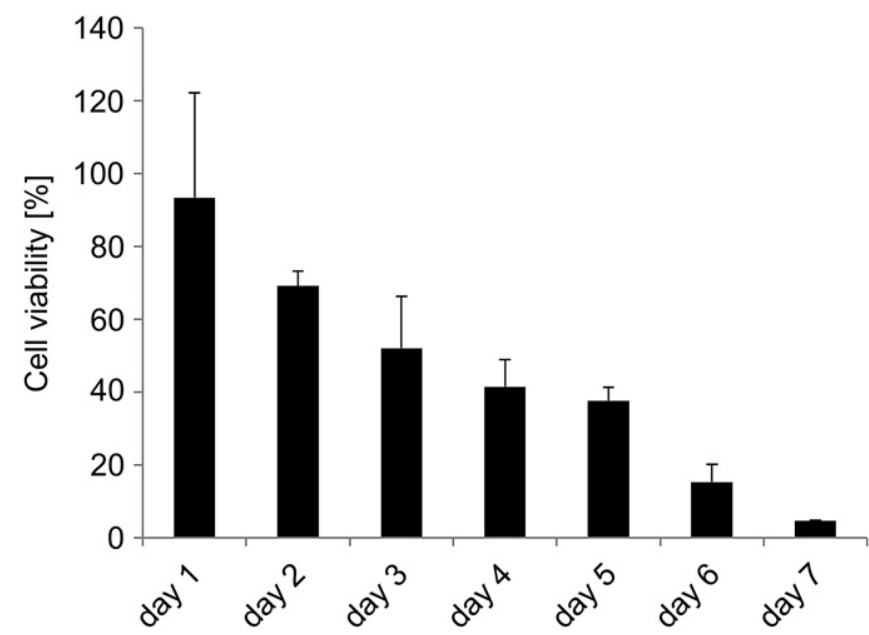

Fig. 3. Cytotoxicity of reprogramming factor-encoding mRNA transfections in HFF1 cells. Cells were transfected with $4 \mu \mathrm{g}$ of mRNA encoding equal amounts of OCT4, SOX2, KLF4 and c-MYC by complexing with $4 \mu \mathrm{l}$ LF as described in Materials and methods. The transfection solution was divided over two 12-wells containing HFF1 cells. Transfections were done every day; seven consecutive transfections were performed. MTT assay was done $24 \mathrm{~h}$ post every transfection. Graphs represent means \pm SD. $n \geq 2$. between the two groups. Of these, 662 genes were significantly upregulated (e.g. IFNB1, CCL5, ISG20, OAS1, MDA5 (IFIH1), RIG-I (DDX58), IRF7, MYD88, ADAR, TRIF (TICAM1)) and 331 genes were significantly down-regulated (e.g. CCNB1, CCNB2 CCNF, CDC20, BAX) in mRNA-transfected fibroblast cells when compared to the mocktransfected fibroblasts (Supplementary Table S3 and S4). The DAVID database was used to functionally annotate these gene lists $[28,29]$. As a result, the three most highly enriched clusters of the 662 upregulated genes represented (1) the response to bacteria or bacterial structures or drugs, (2) innate immune response and (3) regulation of apoptosis (Supplementary Tables S5). The list of upregulated genes was further enriched for KEGG pathways such as the Jak-STAT signaling pathway, RIG-I-like receptor signaling pathway, antigen processing and presentation, the cytosolic DNAsensing pathway, the Toll-like receptor signaling pathway and apoptosis (Supplementary Fig. S1a-c, Supplementary Table S5). The initiation of apoptosis upon mRNA transfection is further supported by the fact that the list of 331 down-regulated genes is highly enriched for genes associated with cell cycle, cytoskeleton and chromosome condensation, which might suggest that proliferation is compromised in mRNA-transfected cells (Supplementary Table S6). Accordingly, the down-regulated genes are significantly involved in cell cycle and p53 signaling pathways (Supplementary Fig. S1d-e and Supplementary Table S6). According to the Interferome database [30], 249 of the 662 up-regulated genes and 40 of the 331 down-regulated genes are so-called interferon-regulated genes (IRGs) (Supplementary Tables S7 and S8).

\subsection{Innate immune response in HFF1 cells induced by reprogramming experiments using different delivery techniques}

The increased expression levels of immune-related genes observed for the microarray-derived transcriptome data were verified by qRT-PCR. We chose to assess the expression of a set of innate immune response-related genes, known to be regulated during retroviral-based reprogramming [25] and relevant at distinct levels of the antiviral innate immune response. They are 
a

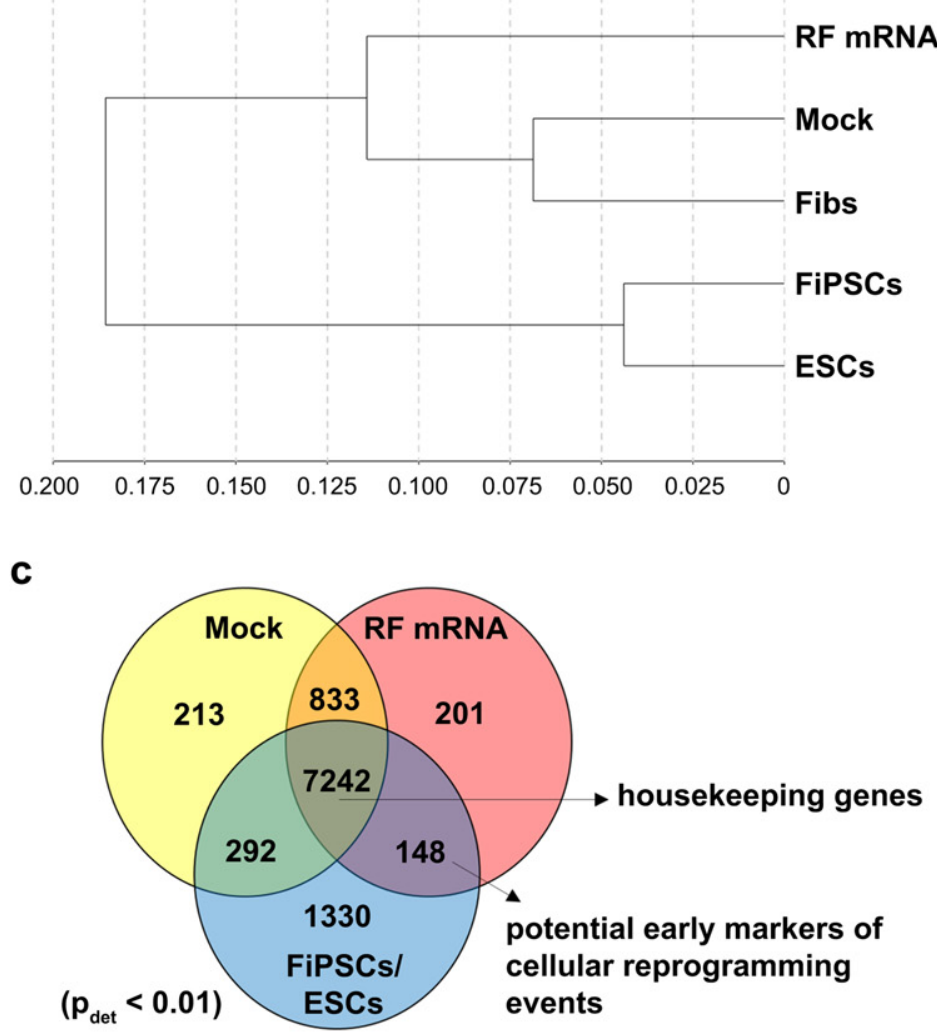

b

\begin{tabular}{|l|c|c|c|c|c|}
\hline \multicolumn{1}{|c|}{$\mathbf{R}^{2}$} & Fibs & Mock & RF mRNA & FiPSCs & ESCs \\
\hline Fibs & 1 & 0.87 & 0.73 & 0.74 & 0.67 \\
\hline Mock & & 1 & 0.84 & 0.75 & 0.68 \\
\hline RF mRNA & & & 1 & 0.60 & 0.56 \\
\hline FiPSCs & & & & 1 & 0.91 \\
\hline ESCs & & & & & 1 \\
\hline
\end{tabular}

d

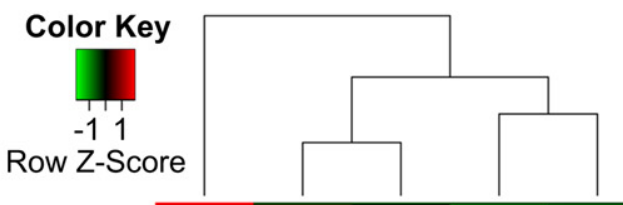

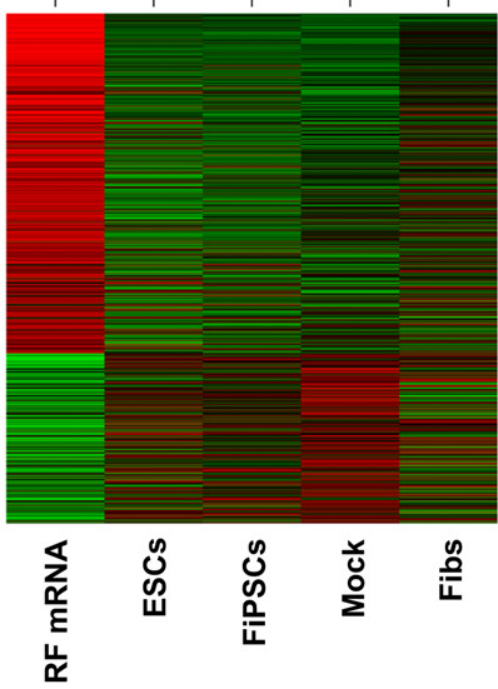

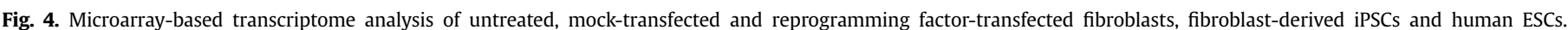

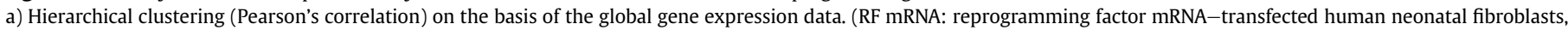

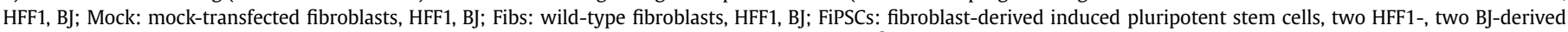

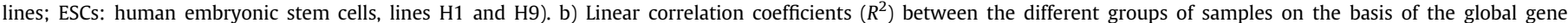

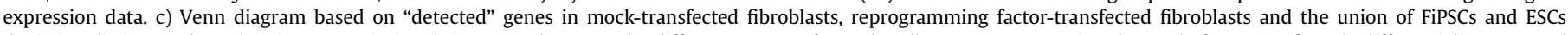

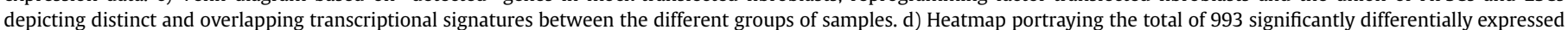

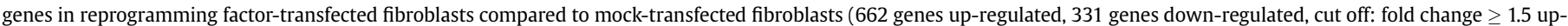

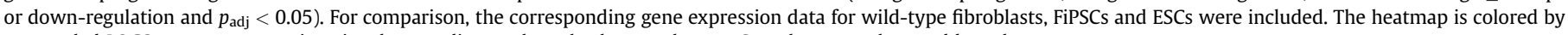
row-scaled LOG2 average expression signals according to the color key on the top. Samples were clustered by column means.

either directly involved in the recognition and binding of exogenous, putatively pathogenic, nucleic acids (RIG-I (DDX58) [35,36], PKR (EIF2AK2) [37,38], OAS1 [37,39] and IFIT1 [40]), key regulators of transcription during the innate immune response (IFNB1 [41]), intra- or extracellular transducers of the stimulus (IL12A (CLMF, NKSF1) [42,43], IRF7 [41,44], STAT2 [45], CCL5 (RANTES) [46,47]) or viral restriction factors (ISG20 [48,49], TRIM5 [50,51]). Interestingly, all of these genes are regulated by interferons (Supplementary Table S7). As shown in Fig. 5, qRT-PCR demonstrated the upregulation of all 11 genes under investigation in both BJ and HFF1 fibroblasts upon transfection of the mixture of unmodified reprogramming factor-encoding mRNAs when compared to mocktransfected control cells.

In a next step, we compared the magnitude of this innate immune response during reprogramming experiments utilizing different delivery techniques. To this end, gene expression levels of the same set of innate immune response-associated genes were assessed after (1) retroviral transduction of a 1:1:1:1 cocktail of the reprogramming factors OCT4, SOX2, KLF4 and c-MYC, (2) one single transfection of the reprogramming factors using equal ratios of the in-house synthesized, unmodified mRNAs by means of lipofection, (3) two subsequent of the aforementioned mRNA lipofections (day1, day2), (4) one transfection of a 1:1:1:1 mixture of the Yamanaka

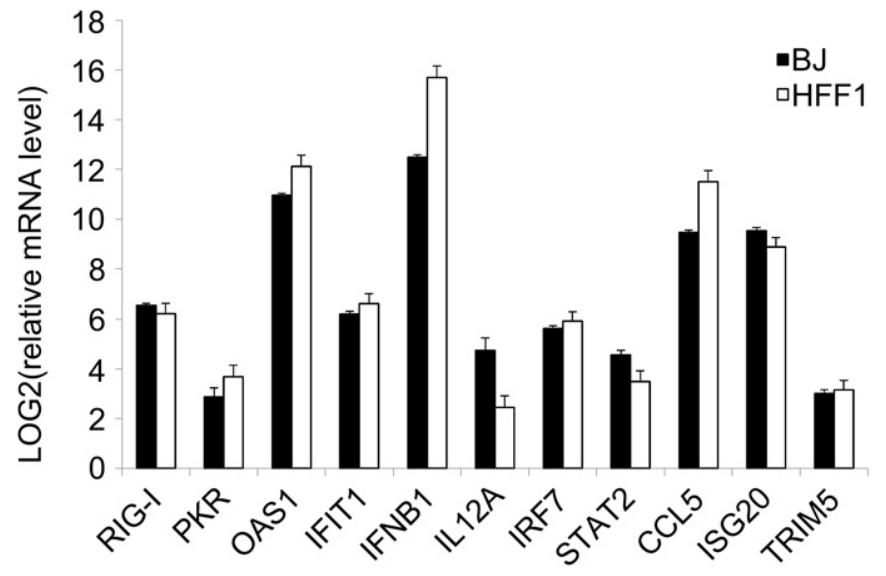

Fig. 5. $q R T-P C R$ of innate immune response-associated transcripts in human fibroblast cells upon mRNA transfection. BJ and HFF1 cells were lipofected with a mixture of mRNAs encoding the reprogramming factors in equal ratios ( $4 \mu \mathrm{g}$ per 6 -well) and harvested $24 \mathrm{~h}$ later for RNA isolation. Bars and error bars represent the average of LOG2 ratios of transfected fibroblasts over mock-transfected controls and SD of technical triplicates. $n=1$ per cell line. 
factors using commercially available, modified mRNAs, (5) one transfection of a mix of pluripotency-promoting miRNAs (miR302s/ 367). Concerning the series of retroviral and miRNA tests, the experimental set-ups were based on either our own or published reprogramming experiments [16,22,52]. Fig. 6a shows that our unmodified reprogramming factor mRNAs, although capped and poly(A)-tailed, induced the strongest up-regulation of immuneassociated genes. Interestingly, the second transfection with the same mRNA cocktail $24 \mathrm{~h}$ after the first one, only slightly increased the expression levels of a few genes, namely, PKR, IL12A, ISG20, yet, does not have an overall augmenting immunogenic effect suggesting that the cellular immune response is already nearly maximally up-regulated after the first transfection. The transcript levels of the delivered reprogramming factors itself, however, were only slightly increased after the second transfection when compared to the levels determined after the first transfection (Fig. 6b). In contrast, immunostaining of the introduced factors after two subsequent transfections revealed that the expression of the translated proteins was very weak (data not shown). Transfection of commercially available modified reprogramming mRNAs, which, in contrast to the mRNAs produced ourselves, contained pseudouridine and 5-methylcytidine-modified nucleotides, resulted in markedly reduced expression levels of almost all immune response-associated genes compared to transfections with our unmodified mRNAs (Fig. 6a). Nonetheless, the incorporation of modified nucleotides did not prevent the up-regulation of the innate interferon response and expression levels of the immune response-associated genes were still elevated when compared to mock-transfected controls. Surprisingly, the number of reprogramming factor transcripts in the cell were notably less when compared to the transfections with the same amount of unmodified mRNAs (Fig. 6b). When cells were transduced with a retroviral reprogramming factor cocktail, expression levels of both immune response-associated and reprogramming factor genes of cells were similar to those detected upon transfection of modified mRNAs. Yet, it must be emphasized that retroviral transcripts are usually not yet fully expressed $24 \mathrm{~h}$ post-transduction as demonstrated by the increase in immunofluorescent staining intensity of reprogramming factors 24,48 and $72 \mathrm{~h}$ post-transduction in our recent publication [25]. Finally, as anticipated, an up-regulation of endogenous reprogramming factors by miRNAs could not be observed as early as $24 \mathrm{~h}$ post-transfection (Fig. 6b). Interestingly however, the transfected miRNAs did not trigger any immune response (Fig. 6a). In contrast to the transfection or transduction of the reprogramming factors, the internalization and functionality of the transfected miRNAs could not be verified by immunostaining of the four factors. Therefore, we chose to analyze PODXL transcript levels instead. PODXL is a surface marker expressed in human ESCs, iPSCs and embryonal carcinoma cells [53] and is activated as early as $24 \mathrm{~h}$ post-retroviral transduction as demonstrated by our previous findings on cellular reprogramminginitiation events [25]. In this respect, the one and two transfections of unmodified RNAs successively up-regulated PODXL as did the cocktail of retroviruses and, to a lesser extent, the combination of miRNAs. Surprisingly, the modified mRNAs did not up-regulate PODXL 24 h post-transfection (Fig. 6c).

We then investigated whether the immune response is specific for the introduced factors by substituting the reprogramming factors with GFP-encoding mRNAs or retroviruses, or scrambled control miRNAs. Logically, as shown in Fig. 7a, apart from normal variation, we did not detect significant alteration in gene expression levels of reprogramming factors. Yet, with all delivery techniques, the expression levels of immune response genes followed the exact pattern and the absolute transcript quantities were similar when compared to those observed for the respective delivery of reprogramming factor cocktails (Fig. 7b).
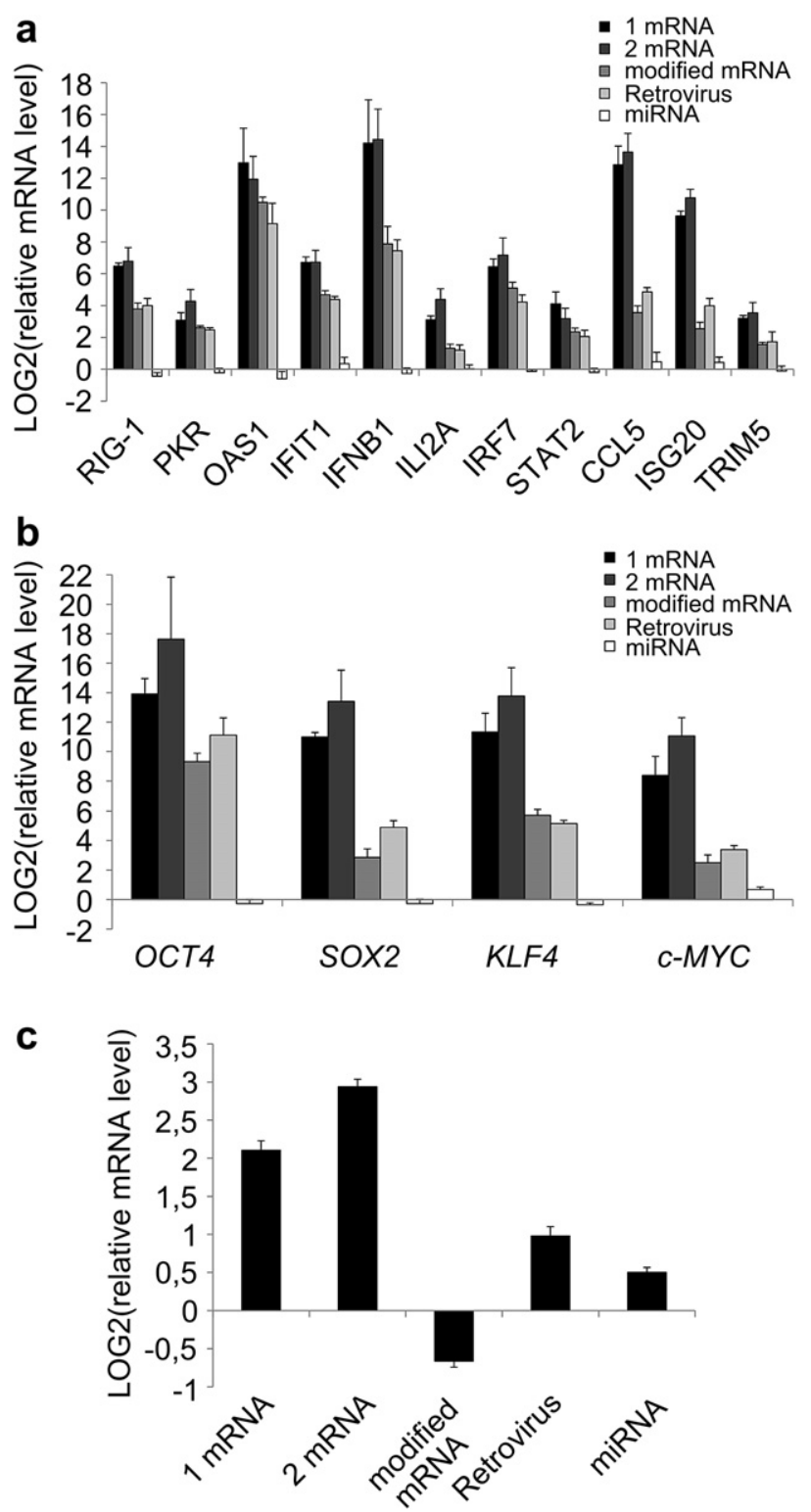

Fig. 6. Expression levels of innate immune response-associated genes, introduced reprogramming factor genes and PODXL in HFF1 cells upon delivery of reprogramming factors by diverse methods. HFF1 cells were transfected with a 1:1:1:1 cocktail of mRNAs encoding OCT4, SOX2, KLF4 and c-MYC. Transfections were carried out once or twice ("1 mRNA", "2 mRNA", respectively; $4 \mu \mathrm{g}$ total per 6-well per transfection). The mRNAs were either synthesized in our laboratory ("mRNA") or commercially bought ("modified mRNA"). Alternatively, HFF1 cells were transduced once with a 1:1:1:1 combination of retroviruses encoding OCT4, SOX2, KLF4 and c-MYC or transfected once with a 1:1:1:1:1 mix composed of the miRNAs miR302a, miR302b, miR302c, miR302d and miR367 (100 pmol total per 6-well). All samples were harvested $24 \mathrm{~h}$ after the last transfection/transduction for RNA isolation. a) Levels of innate immune responseassociated transcripts. b) Expression levels of the reprogramming factor genes. c) PODXL transcript levels. Bars and error bars represent the average of LOG2 ratios of transfected/transduced fibroblasts over mock-transfected/-transduced controls and SD. $n=6$ for " 1 mRNA"; $n=4$ for " 2 mRNA"; $n=3$ for "Retrovirus", "modified mRNA" and "miRNA".

3.5. Effect of chemical treatments on innate immune response in HFF1 cells upon transfection of mRNAs encoding reprogramming factors

As demonstrated above, the main roadblock in our mRNA reprogramming experiments was the activation of innate immune response resulting in decreased proliferation and increased loss of cell viability. This might have been a result of the up-regulation 

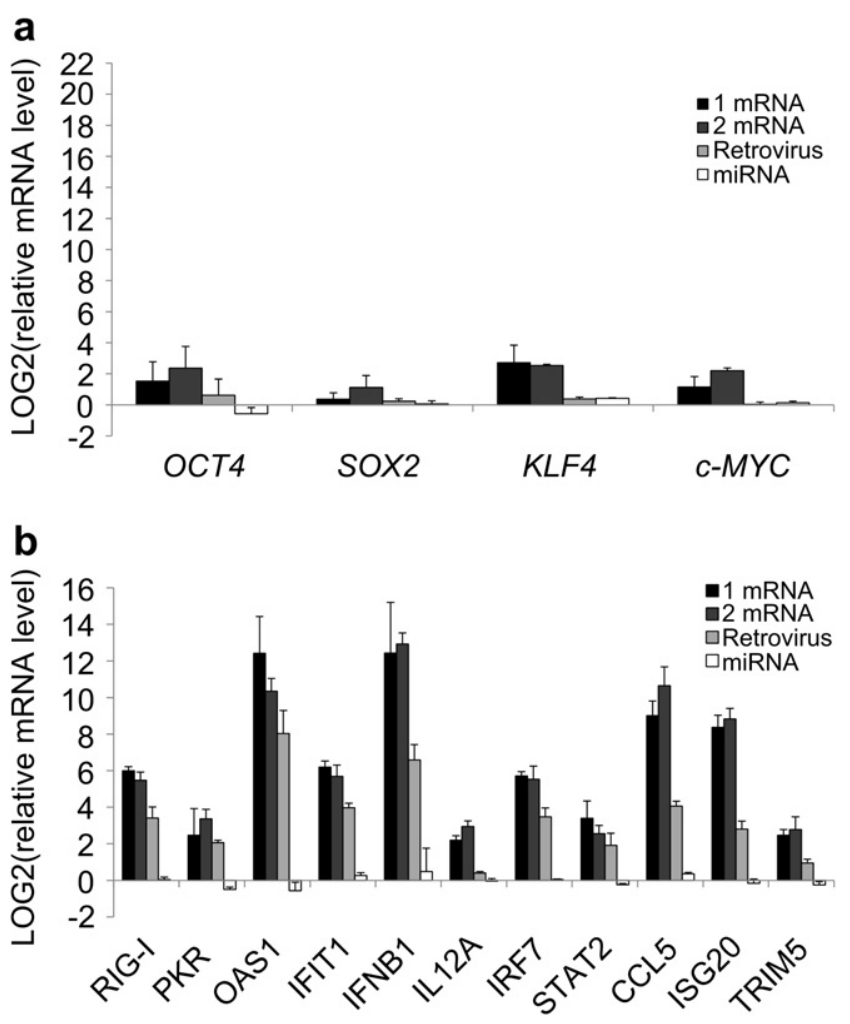

Fig. 7. Expression levels of reprogramming factor genes and innate immune responseassociated genes in HFF1 cells upon delivery of control genes by diverse methods. Repetition of the HFF1 transfection/transduction experiments as described in Fig. 6. Yet, this time, the total amount of mRNAs and miRNAs used for reprogramming were substituted with the same amount of GFP-encoding mRNA ("1 mRNA", " 2 mRNA"; $4 \mu \mathrm{g}$ total per 6-well per transfection) or a scrambled miRNA ( 100 pmol total per 6-well). Similarly, cells were transduced with a GFP-encoding retrovirus equivalent to the amount of retrovirus encoding one of the reprogramming factors in the reprogramming OSKM cocktail. a) Expression levels of the reprogramming factor genes. b) Levels of innate immune response-associated transcripts. Bars and error bars represent the average of LOG2 ratios of transfected/transduced fibroblasts over mock-transfected/transduced controls and SD. $n=6$ for " 1 mRNA"; $n=4$ for "2 mRNA"; $n=3$ for "Retrovirus" and "miRNA".

of one of the key innate immune response regulators, type I interferon IFNB1. Interestingly, Yang et al., adopting an integrated genomics approach, identified Nabumetone, a nonsteroidal antiinflammatory drug, significantly enhanced the induction of pluripotency in mouse cells [54]. With this evidence, we next searched for substances that might suppress the innate immune response we observed from our microarray-based transcriptome data, thereby, increasing mRNA-based reprogramming efficiency. We evaluated the ability of five substances to prevent up-regulation of the different innate immune response-associated genes by means of qRT-PCR when they were incubated before, during and after delivery of the mRNA complexes.

The first molecule to suppress the innate interferon response we tested, was B18R - a virus-encoded decoy receptor specific for type I interferons of various species, which neutralizes signaling via type I interferon receptors. B18R was described to prevent transmembrane signaling and transcriptional regulation of the interferon-regulated genes $[55,56]$ and has been used in the only mRNAbased reprogramming protocol published so far [14]. As presented in Fig. 8a, in our hands this treatment did not show any measurable decrease of innate immune response even though all of these genes are known to be IRGs as determined by the Interferome database. Because this result was in line with our previous finding that B18R did not have any effect on the efficiency of inducing pluripotency in fibroblast cells [25], we did not pursue investigations using B18R further.

Secondly, chloroquine, originally synthesized as an anti-malaria drug, intrigued us to examine its ability to suppress the immune response initiated by mRNA delivery. This lysosomotropic substance has been reported to exert pleiotropic functions such as enhancing transfection efficiency by facilitating endosomal escape and/or diminishing lysosomal degradation [57,58]. Moreover, chloroquine has been shown to have several immunemodulatory, anti-inflammatory effects such as the ability to inhibit TNF- $\alpha$, IL-1 $\beta$ and IL-6 production in lipopolysaccharide-stimulated human monocytes/macrophages [59], to reduce type I interferon (IFN- $\alpha$ ) production in CpG-DNA- or viral ssRNA-stimulated plamacytoidderived dendritic cells or IL-12 production in ssRNA poly(U)stimulated monocyte-derived dendritic cells $[43,60]$. We tested three different concentrations of chloroquine and noticed a strong concentration-dependent cytotoxic effect. Even though the expression levels of a few innate interferon response-associated genes (RIG-I, OAS1, CCL5, ISG20) were slightly reduced upon chloroquine treatment when compared to mock-transfected controls (Fig. 8b), these reductions were not sufficient to balance out the cytotoxic effects of this molecule.

Trichostatin A (TSA), a streptomyces metabolite, was first discovered as an antifungal antibiotic and later as an inhibitor of mammalian histone deacetylases [61,62]. Moreover, it was reported to block nuclear translocation of the transcription factor IRF7 and as a consequence numerous interferons and other pro-inflammatory cytokines [63]. When applied at the suggested concentrations, TSA showed no significant effects on the expression levels of genes tested (Fig. 8c). When used at the highest concentration (500 nM), expression levels of CCL5 and ISG20 were reduced when compared to untreated, mRNA-transfected samples, however, the absolute gene expression values were still much higher than those determined for mock-transfected controls.

Finally, we tried Pepinh-TRIF and Pepinh-MYD, two peptide inhibitors designed to contain domains of the signaling adapter molecules TRIF and MyD88, thus facilitating interaction with the respective pattern-recognition receptors TLR3 or TLR7/8 [64,65]. Competing with endogenous TRIF and MyD88 for association with those TLRs, these two peptide inhibitors could attenuate signaling to the nucleus, thereby, suppressing the up-regulation of innate immune response genes. However, treatment of HFF1 cells with each of these peptides at the suggested concentration of $20 \mu \mathrm{M}$, did not lead to a marked reduction in expression of any of the immune response-associated genes (Fig. 8d).

\section{Discussion}

The ability of our method to transfect human fibroblast cells with mRNA successfully was demonstrated by the high levels of expression of GFP after m(GFP) lipofection. Moreover, when mRNAs encoding the Yamanaka factors (OSKM) were introduced into HFF1 cells (human neonatal fibroblasts), the proteins were expressed within the cell nucleus as one would expect. Daily transfections with factor-encoding mRNAs caused tremendous cytotoxicity with no viable cells after seven consecutive transfections. Despite our expertise and experience in producing induced pluripotent stem cells (iPSCs) [6,20-22], several attempts to apply our mRNAmediated technique to fully reprogram HFF1 cells into induced pluripotent cells failed because of this progressive cell death. Accordingly, also Angel and Yanik noticed severe cell damage upon repeated transfection with mRNA [15]. These observations spurred us to investigate the barriers preventing the successful induction of pluripotency in fibroblast cells. 

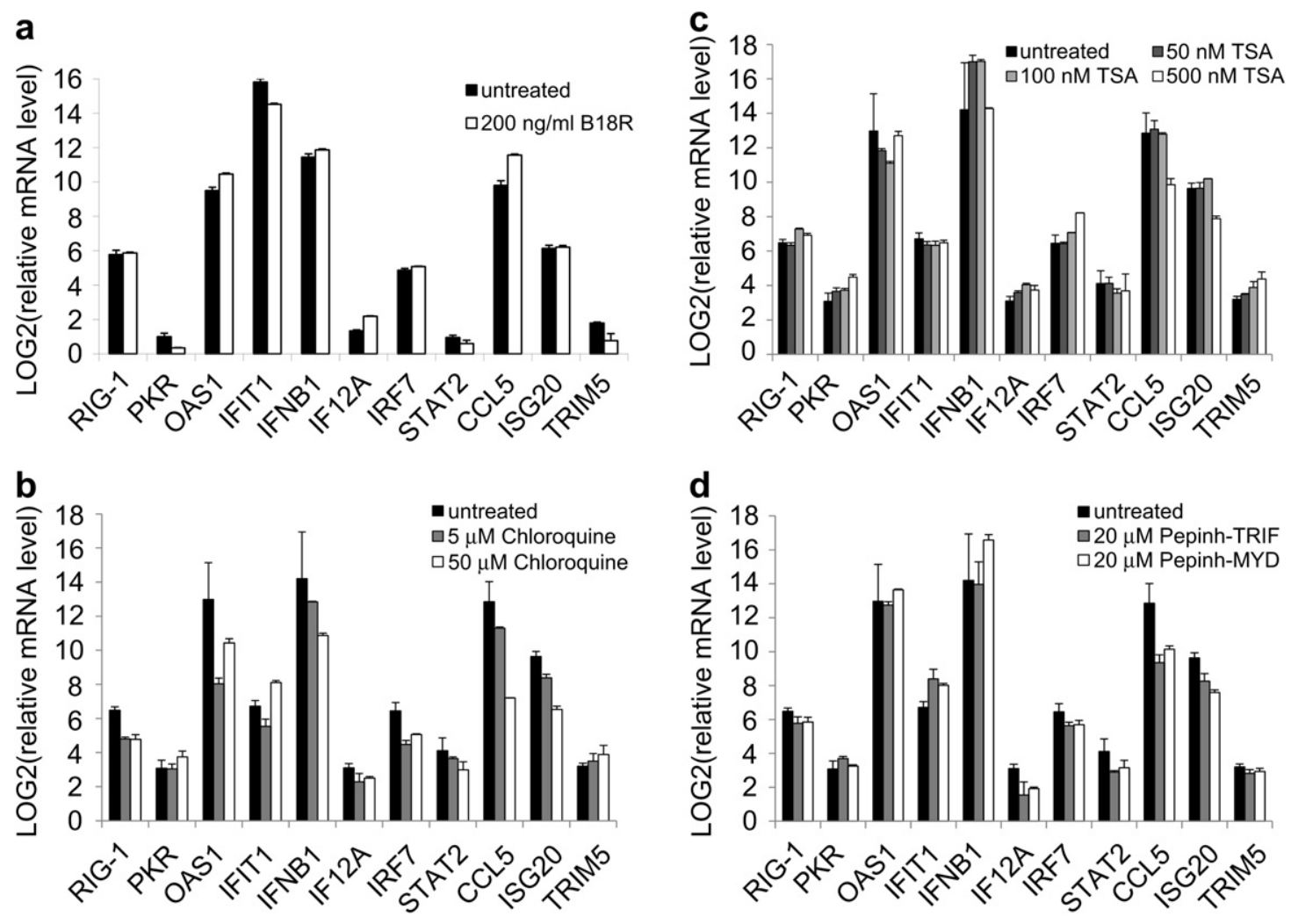

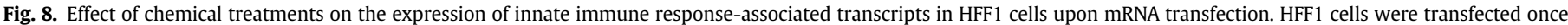

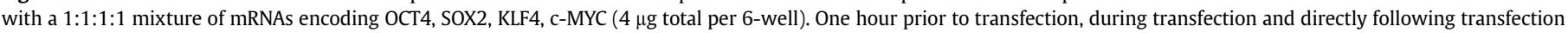

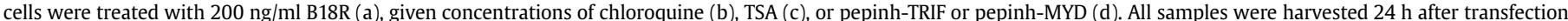

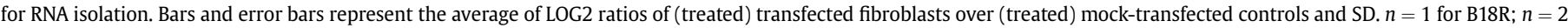
for Pepinh-TRIF; $n=3$ for Pepinh-MYD; $n=2$ for each concentration of TSA and chloroquine.

Despite the high expression levels of the exogenously delivered reprogramming factors by means of mRNA lipofection, a general switch in the global gene expression pattern from the fibroblasttranscriptome toward the transcriptome of a pluripotent cell (down-regulation of fibroblast genes, up-regulation of pluripotencyassociated genes) was not apparent at $24 \mathrm{~h}$ post-transfection of the reprogramming factor-encoding mRNAs. However, we did observe an overlap of the transcriptomes of reprogramming factortransfected fibroblasts and the union of human FiPSCs and ESCs and the relevance for cellular reprogramming of these highlighted genes warrants further investigation. This is supported by Plews et al., who showed an activation of pluripotency-associated genes upon delivery of mRNAs encoding the reprogramming factors into human fibroblasts, however, complete reprogramming to fully characterizable iPSCs was not attained [66]. The transcriptome data obtained by microarray analysis allowed us to conclude that the key roadblock during reprogramming by means of frequent mRNA transfections is a strong innate immune reaction initiated by cellular mechanisms recognizing foreign nucleic acids, as is the case during microbial or viral infections. This is in line with recent reports [15]. Based on the findings reported in the review of Yoneyama and Fujita [41], the cascade of events provoked in our mRNA-transfected cells can be conceived as follows: first, the transfected, purified, in vitro synthesized reprogramming factor-encoding mRNAs are recognized by pattern-recognition receptors (PRRs). Because the secondary structure of the transfected mRNAs is elusive, it is difficult to predict which PRRs are responsible for the detection of the exogenous mRNAs. In principle, given that lipofected nucleic acids are primarily taken up via endocytotic routes [67], TLR3 and TLR7/8 in the endosomes should be the primarily involved PRRs [41]. Yet, it is known that TLR3 and TLR7/8 are preferentially expressed in immune cells [41]. Accordingly, the microarray data suggest that TLR3 is only expressed in fibroblasts upon mRNA transfection and that TLR7/8 receptors are not expressed in any of the samples under investigation. It is tempting to speculate that cytoplasmic receptors such as RIG-I and MDA5 are essential for the recognition of exogenous mRNA when accessible in the cytoplasm, e.g. after endosomal escape of the transfected mRNA [67]. Concerning these, our microarray data revealed low level expression of both of these receptors in mocktransfected control fibroblasts and strong up-regulation upon mRNA transfection (RIG-I (DDX58): 47-fold up-regulation, MDA5 (IFIH1): 72-fold up-regulation). Indeed, it has been shown by Kato et al. that induction of type I interferons upon infection of mouse embryonic fibroblasts with several single-stranded RNA viruses was RIG-I- but not TLR-dependent [68]. Although it is not completely clear, which of the suggested receptor(s) is/are eventually responsible for the detection of the foreign mRNAs, our results emphasize that the up-regulation of the receptors involved, triggered an increased translation of type I interferons (such as IFNB1) and proinflammatory cytokines (such as CCL2, CCL5, IL10 and IL12A). In turn, type I interferons provoked positive feedback regulation, which enhanced different defense mechanisms against the putative pathogen attack at different levels. Correspondingly, our data suggested that within the mRNA-transfected cells, PRRs like RIG-I, MDA5, including those, which elicit antiviral/antimicrobial activities, such as OAS1,PKR and $A D A R$, were significantly up-regulated together with a number of signaling molecules (JUN (as part of the transcription factor AP-1), IRF7, MYD88, IRAK4 etc.). As a result, protein translation was potentially blocked, the foreign nucleic acid degraded and apoptosis induced. In support of this effect, we 
detected down-regulation of interferon-responsive cell cycle regulating genes (CDC20, CCNB1, CCNF). In line with our results, Johnston and co-workers reported induction of IFNB1, PKR, OAS1 as well as induction of cell death in human dermal fibroblasts stimulated with dsRNA [69]. It is worth mentioning that interferons as well as the up-regulated pro-inflammatory cytokines act in an autocrine and paracrine fashion, i.e. they transduce their signal into neighboring cells activating the same innate immune mechanisms in those cells and sensitizing them toward foreign nucleic acids [15,41]. Taken together, these findings are in line with our previous observation with respect to retrovirally transduced fibroblasts, i.e. one of the main obstacles to overcome during retroviral-based reprogramming experiments is the innate immune response, which is triggered in the target cells [25].

Despite the lack of TLR7/8 expression in HFF1 and BJ fibroblasts, the TLR-associated adapter molecules MYD88 and TRIF as well as the signaling molecule IRF7 were highly up-regulated upon transfection of mRNAs encoding the reprogramming factors. Therefore, we were still convinced that both Pepinh-TRIF and Pepinh-MYD as well as TSA would modulate the innate immune response in mRNAtransfected fibroblasts. Unfortunately, none of the chemicals tested showed significant down-regulation of the assessed immune response-associated genes in our hands, although their inhibitory function on distinct levels of the innate immune response activated upon non-viral mRNA transfection was promising.

Beside the quest for alternative ways of suppressing the immune response in mRNA-mediated induction of pluripotency in human somatic cells, it is of importance to investigate the potential of small molecules to increase the efficiency of this reprogramming approach. Several chemical compounds such as the histone deacetylase inhibitor VPA and the cyclic AMP analog 8-Br-cAMP, which transiently down-regulate p53 $[4,6]$ were shown to enhance the induction of pluripotency in somatic cells. Furthermore, treatment of cells with sodium butyrate, a histone deacetylase inhibitor, and other molecules, which modulate distinct signaling pathways, including PS48, an activator of $3^{\prime}$-phosphoinositide-dependent kinase-1 (PDK1) [8], MEK inhibitor PD0325901, GSK3 $\beta$ inhibitor CHIR99021, TGF- $\beta$ /Activin/Nodal receptor inhibitor A-83-01, ROCK inhibitor HA-100 and human leukemia inhibitory factor (LIF) [7], also resulted in increased reprogramming efficiencies. We, therefore, propose that these small molecule cocktails should be tested and also incorporated into mRNA-based cellular reprogramming protocols in the future.

\section{Conclusions}

We have clearly demonstrated the functionality of our mRNA transfection protocol in terms of expression of the translated proteins in the nucleus. Full reprogramming of human neonatal fibroblasts into iPSCs by means of repeated transfection of mRNAs encoding the Yamanaka factors was impeded by activated innate immune response. We intensively investigated this activation by means of comparative global transcriptome analysis and qRT-PCR of selected genes within the innate immune response pathway. The comparison of the immune responses triggered by different delivery methods revealed that the immune response induced by unmodified mRNA was the highest, followed by retroviral transduction and modified mRNA, which induced similar expression levels of immune-associated genes. In contrast, miRNA transfections did not induce a significant response. Supplementation with various anti-inflammatory compounds (B18R, chloroquine, TSA, Pepinh-TRIF, Pepinh-MYD) did not induce a down-regulation of immune response-associated genes in our assays. In summary, our data provide an important basis for developing new approaches for suppressing immune reactions, be it the use of other chemical compounds and/or siRNA(s), thus, allowing multiple mRNA transfections to facilitate efficient mRNA-mediated induction of pluripotency in human somatic cells.

\section{Acknowledgments}

Geertrui Tavernier is a doctoral fellow of the Institute for the Promotion of Innovation through Science and Technology in Flanders (IWT-Vlaanderen). Contributions of Katharina Drews were also made possible by partial funding from the Deutsche Forschungsgemeinschaft (DFG, www.dfg.de) through the Berlin-Brandenburg School for Regenerative Therapies (BSRT, www.bsrt.de) GSC 203. James Adjaye acknowledges support from the Max Planck Society and the [BMBF], partners of the ERASysBio + initiative supported under the EU ERA-NET Plus scheme in FP7.

\section{Appendix. Supplementary material}

Supplementary material associated with this article can be found, in the online version, at doi:10.1016/j.biomaterials.2012.02. 025 .

\section{References}

[1] Takahashi K, Yamanaka S. Induction of pluripotent stem cells from mouse embryonic and adult fibroblast cultures by defined factors. Cell 2006;126(4): 663-76.

[2] Takahashi K, Tanabe K, Ohnuki M, Narita M, Ichisaka T, Tomoda K, et al. Induction of pluripotent stem cells from adult human fibroblasts by defined factors. Cell 2007;131(5):861-72.

[3] Yu J, Vodyanik MA, Smuga-Otto K, Antosiewicz-Bourget J, Frane JL, Tian S, et al. Induced pluripotent stem cell lines derived from human somatic cells. Science 2007;318(5858):1917-20.

[4] Huangfu D, Osafune K, Maehr R, Guo W, Eijkelenboom A, Chen S, et al. Induction of pluripotent stem cells from primary human fibroblasts with only Oct4 and Sox2. Nat Biotechnol 2008;26(11):1269-75.

[5] Nakagawa M, Koyanagi M, Tanabe K, Takahashi $K$, Ichisaka T, Aoi T, et al Generation of induced pluripotent stem cells without Myc from mouse and human fibroblasts. Nat Biotechnol 2008;26(1):101-6.

[6] Wang Y, Adjaye J. A cyclic AMP analog, 8-Br-cAMP, enhances the induction of pluripotency in human fibroblast cells. Stem Cell Rev 2011;7(2):331-41.

[7] Yu J, Chau KF, Vodyanik MA, Jiang J, Jiang Y. Efficient feeder-free episomal reprogramming with small molecules. PLoS One 2011;6(3):e17557.

[8] Zhu S, Li W, Zhou H, Wei W, Ambasudhan R, Lin T, et al. Reprogramming of human primary somatic cells by OCT4 and chemical compounds. Cell Stem Cell 2010;7(6):651-5.

[9] Okita K, Nakagawa M, Hyenjong H, Ichisaka T, Yamanaka S. Generation of mouse induced pluripotent stem cells without viral vectors. Science 2008; 322(5903):949-53.

[10] Yu J, Hu K, Smuga-Otto K, Tian S, Stewart R, Slukvin II , et al. Human induced pluripotent stem cells free of vector and transgene sequences. Science 2009; 324(5928):797-801.

[11] Kaji K, Norrby K, Paca A, Mileikovsky M, Mohseni P, Woltjen K. Virus-free induction of pluripotency and subsequent excision of reprogramming factors. Nature 2009;458(7239):771-5.

[12] Sommer CA, Sommer AG, Longmire TA, Christodoulou C, Thomas DD, Gostissa $\mathrm{M}$, et al. Excision of reprogramming transgenes improves the differentiation potential of iPS cells generated with a single excisable vector. Stem Cells 2010;28(1):64-74.

[13] Zhou H, Wu S, Joo JY, Zhu S, Han DW, Lin T, et al. Generation of induced pluripotent stem cells using recombinant proteins. Cell Stem Cell 2009;4(5): 381-4.

[14] Warren L, Manos PD, Ahfeldt T, Loh YH, Li H, Lau F, et al. Highly efficient reprogramming to pluripotency and directed differentiation of human cells with synthetic modified mRNA. Cell Stem Cell 2010;7(5):618-30.

[15] Angel M, Yanik MF. Innate immune suppression enables frequent transfection with RNA encoding reprogramming proteins. PLoS One 2010;5(7):e11756.

[16] Miyoshi N, Ishii H, Nagano H, Haraguchi N, Dewi DL, Kano Y, et al. Reprogramming of mouse and human cells to pluripotency using mature microRNAs. Cell Stem Cell 2011;8(6):633-8.

[17] Wang P, Na J. Mechanism and methods to induce pluripotency. Protein Cell 2011;2(10):792-9.

[18] Rejman J, Tavernier G, Bavarsad N, Demeester J, De Smedt SC. mRNA transfection of cervical carcinoma and mesenchymal stem cells mediated by cationic carriers. J Control Release 2010;147(3):385-91. 
[19] Tavernier G, Andries O, Demeester J, Sanders NN, De Smedt SC, Rejman J. mRNA as gene therapeutic: how to control protein expression. J Control Release 2011;150(3):238-47.

[20] Prigione A, Fauler B, Lurz R, Lehrach H, Adjaye J. The senescence-related mitochondrial/oxidative stress pathway is repressed in human induced pluripotent stem cells. Stem Cells 2010;28(4):721-33.

[21] Prigione A, Lichtner B, Kuhl H, Struys EA, Wamelink M, Lehrach $H$, et al. Human induced pluripotent stem cells harbor homoplasmic and heteroplasmic mitochondrial DNA mutations while maintaining human embryonic stem cell-like metabolic reprogramming. Stem Cells 2011;29(9):1338-48.

[22] Wolfrum K, Wang Y, Prigione A, Sperling K, Lehrach H, Adjaye J. The LARGE principle of cellular reprogramming: lost, acquired and retained gene expression in foreskin and amniotic fluid-derived human iPS cells. PLoS One 2010;5(10):e13703.

[23] Tavernier G, Wolfrum K, Demeester J, De Smedt SC, Adjaye J, Rejman J. Activation of pluripotency-associated genes in mouse embryonic fibroblasts by non-viral transfection with in vitro-derived mRNAs encoding Oct4, Sox2, Klf4 and cMyc. Biomaterials 2012;33(2):412-7.

[24] Nair SK, Boczkowski D, Morse M, Cumming RI, Lyerly HK, Gilboa E. Induction of primary carcinoembryonic antigen (CEA)-specific cytotoxic T lymphocytes in vitro using human dendritic cells transfected with RNA. Nat Biotechnol 1998;16(4):364-9.

[25] Mah N, Wang Y, Liao MC, Prigione A, Jozefczuk J, Lichtner B, et al. Molecular insights into reprogramming-initiation events mediated by the OSKM gene regulatory network. PLoS One 2011;6(8):e24351.

[26] R Development Core Team. R. A language and environment for statistical computing. R Foundation for Statistical Computing. Available from: http:// www.R-project.org; 2010.

[27] Warnes GR, Bolker B, Bonebakker L, Gentleman R, Liaw WHA, Lumley T, et al. Gplots: various $\mathrm{R}$ programming tools for plotting data. $\mathrm{R}$ package version 2.8.0. Available from: http://CRAN.R-project.org/package=gplots; 2010.

[28] Dennis Jr G, Sherman BT, Hosack DA, Yang J, Gao W, Lane HC, et al. DAVID: Database for Annotation, Visualization, and Integrated Discovery. Genome Biol 2003;4(5):P3.

[29] Huang da W, Sherman BT, Lempicki RA. Systematic and integrative analysis of large gene lists using DAVID bioinformatics resources. Nat Protoc 2009;4(1): 44-57.

[30] Samarajiwa SA, Forster S, Auchettl K, Hertzog PJ. INTERFEROME: the database of interferon regulated genes. Nucleic Acids Res 2009;37(Database issue): D852-7.

[31] Edgar R, Domrachev M, Lash AE. Gene expression omnibus: NCBI gene expression and hybridization array data repository. Nucleic Acids Res 2002; 30(1):207-10.

[32] Brink TC, Demetrius L, Lehrach H, Adjaye J. Age-related transcriptional changes in gene expression in different organs of mice support the metabolic stability theory of aging. Biogerontology 2009;10(5):549-64.

[33] Livak KJ, Schmittgen TD. Analysis of relative gene expression data using realtime quantitative PCR and the 2(-Delta Delta C(T)) method. Methods 2001; 25(4):402-8

[34] Rautsi O, Lehmusvaara S, Salonen T, Hakkinen K, Sillanpaa M, Hakkarainen T, et al. Type I interferon response against viral and non-viral gene transfer in human tumor and primary cell lines. J Gene Med 2007;9(2):122-35.

[35] Binder M, Eberle F, Seitz S, Mucke N, Huber CM, Kiani N, et al. Molecular mechanism of signal perception and integration by the innate immune sensor retinoic acid-inducible gene-I (RIG-I). J Biol Chem 2011;286(31): 27278-87.

[36] Pichlmair A, Schulz O, Tan CP, Naslund TI, Liljestrom P, Weber F, et al. RIG-Imediated antiviral responses to single-stranded RNA bearing $5^{\prime}$-phosphates. Science 2006;314(5801):997-1001.

[37] Baglioni C, Minks MA, De Clercq E. Structural requirements of polynucleotides for the activation of $\left(2^{\prime}-5^{\prime}\right)$ An polymerase and protein kinase. Nucleic Acids Res 1981;9(19):4939-50.

[38] McAllister CS, Samuel CE. The RNA-activated protein kinase enhances the induction of interferon-beta and apoptosis mediated by cytoplasmic RNA sensors. J Biol Chem 2009;284(3):1644-51.

[39] Kristiansen H, Scherer CA, McVean M, Iadonato SP, Vends S, Thavachelvam K, et al. Extracellular 2'-5' oligoadenylate synthetase stimulates RNase L-independent antiviral activity: a novel mechanism of virus-induced innate immunity. J Virol 2010;84(22):11898-904.

[40] Pichlmair A, Lassnig C, Eberle CA, Gorna MW, Baumann CL, Burkard TR, et al. IFIT1 is an antiviral protein that recognizes 5 '-triphosphate RNA. Nat Immunol 2011;12(7):624-30.

[41] Yoneyama M, Fujita T. Recognition of viral nucleic acids in innate immunity. Rev Med Virol 2010;20(1):4-22

[42] Tahara H, Lotze MT. Antitumor effects of interleukin-12 (IL-12): applications for the immunotherapy and gene therapy of cancer. Gene Ther 1995;2(2): 96-106.

[43] Katashiba Y, Miyamoto R, Hyo A, Shimamoto K, Murakami N, Ogata M, et al. Interferon-alpha and interleukin-12 are induced, respectively, by double- stranded DNA and single-stranded RNA in human myeloid dendritic cells. Immunology 2011;132(2):165-73.

[44] Kawai T, Sato S, Ishii KJ, Coban C, Hemmi H, Yamamoto M, et al. Interferonalpha induction through Toll-like receptors involves a direct interaction of IRF7 with MyD88 and TRAF6. Nat Immunol 2004;5(10):1061-8.

[45] Uddin S, Chamdin A, Platanias LC. Interaction of the transcriptional activator Stat-2 with the type I interferon receptor. J Biol Chem 1995;270(42): 24627-30.

[46] Schall TJ, Bacon K, Toy KJ, Goeddel DV. Selective attraction of monocytes and T lymphocytes of the memory phenotype by cytokine RANTES. Nature 1990 347(6294):669-71.

[47] Genin P, Algarte M, Roof P, Lin R, Hiscott J. Regulation of RANTES chemokine gene expression requires cooperativity between NF-kappa B and IFNregulatory factor transcription factors. J Immunol 2000;164(10):5352-61.

[48] Espert L, Degols G, Gongora C, Blondel D, Williams BR, Silverman RH, et al ISG20, a new interferon-induced RNase specific for single-stranded RNA defines an alternative antiviral pathway against RNA genomic viruses. J Biol Chem 2003;278(18):16151-8.

[49] Zhou Z, Wang N, Woodson SE, Dong Q, Wang J, Liang Y, et al. Antiviral activities of ISG20 in positive-strand RNA virus infections. Virology 2011; 409(2):175-88.

[50] Rold CJ, Aiken C. Proteasomal degradation of TRIM5alpha during retrovirus restriction. PLoS Pathog 2008;4(5):e1000074.

[51] Pertel T, Hausmann S, Morger D, Zuger S, Guerra J, Lascano J, et al. TRIM5 is an innate immune sensor for the retrovirus capsid lattice. Nature 2011 472(7343):361-5

[52] Anokye-Danso F, Trivedi CM, Juhr D, Gupta M, Cui Z, Tian Y, et al. Highly efficient miRNA-mediated reprogramming of mouse and human somatic cells to pluripotency. Cell Stem Cell 2011;8(4):376-88.

53] Tan HL, Fong WJ, Lee EH, Yap M, Choo A. mAb 84, a cytotoxic antibody that kills undifferentiated human embryonic stem cells via oncosis. Stem Cells 2009;27(8):1792-801.

[54] Yang CS, Lopez CG, Rana TM. Discovery of nonsteroidal anti-inflammatory drug and anticancer drug enhancing reprogramming and induced pluripotent stem cell generation. Stem Cells 2011;29(10):1528-36.

[55] Colamonici OR, Domanski P, Sweitzer SM, Larner A, Buller RM. Vaccinia virus B18R gene encodes a type I interferon-binding protein that blocks interferon alpha transmembrane signaling. J Biol Chem 1995;270(27):15974-8.

[56] Symons JA, Alcami A, Smith GL. Vaccinia virus encodes a soluble type interferon receptor of novel structure and broad species specificity. Cell 1995 81(4):551-60.

[57] Cooper RG, Magwere T. Chloroquine: novel uses \& manifestations. Indian J Med Res 2008;127(4):305-16.

[58] Wattiaux R, Laurent N, Wattiaux-De Coninck S, Jadot M. Endosomes, lysosomes: their implication in gene transfer. Adv Drug Deliv Rev 2000;41(2): 201-8.

[59] Jang CH, Choi JH, Byun MS, Jue DM. Chloroquine inhibits production of TNF-alpha, IL-1beta and IL-6 from lipopolysaccharide-stimulated human monocytes macrophages by different modes. Rheumatology (Oxford) 2006;45(6):703-10.

[60] Diebold SS, Kaisho T, Hemmi H, Akira S, Reis e Sousa C. Innate antiviral responses by means of TLR7-mediated recognition of single-stranded RNA Science 2004:303(5663):1529-31.

[61] Tsuji N, Kobayashi M, Nagashima K, Wakisaka Y, Koizumi K. A new antifungal antibiotic, trichostatin. J Antibiot (Tokyo) 1976;29(1):1-6.

[62] Yoshida M, Kijima M, Akita M, Beppu T. Potent and specific inhibition of mammalian histone deacetylase both in vivo and in vitro by trichostatin A. J Biol Chem 1990;265(28):17174-9.

63] Salvi V, Bosisio D, Mitola S, Andreoli L, Tincani A, Sozzani S. Trichostatin A blocks type I interferon production by activated plasmacytoid dendritic cells. Immunobiology 2010;215(9-10):756-61.

64] Loiarro M, Sette C, Gallo G, Ciacci A, Fanto N, Mastroianni D, et al. Peptidemediated interference of TIR domain dimerization in MyD88 inhibits interleukin-1-dependent activation of NF-\{kappa\}B. J Biol Chem 2005;280(16): 15809-14.

65] Toshchakov VU, Basu S, Fenton MJ, Vogel SN. Differential involvement of BB loops of toll-IL-1 resistance (TIR) domain-containing adapter proteins in TLR4versus TLR2-mediated signal transduction. J Immunol 2005;175(1):494-500.

[66] Plews JR, Li J, Jones M, Moore HD, Mason C, Andrews PW, et al. Activation of pluripotency genes in human fibroblast cells by a novel mRNA based approach. PLoS One 2010;5(12):e14397.

[67] Khalil IA, Kogure K, Akita H, Harashima H. Uptake pathways and subsequent intracellular trafficking in nonviral gene delivery. Pharmacol Rev 2006;58(1): $32-45$.

[68] Kato H, Sato S, Yoneyama M, Yamamoto M, Uematsu S, Matsui K, et al. Cell type-specific involvement of RIG-I in antiviral response. Immunity 2005 23(1):19-28.

[69] Johnston JB, Nazarian SH, Natale R, McFadden G. Myxoma virus infection of primary human fibroblasts varies with cellular age and is regulated by host interferon responses. Virology 2005;332(1):235-48. 